\title{
Safety Operation Simulation of Teaching Robot Based on VIRTOOLS
}

\author{
Liang Zhang ${ }^{1,3}$, Rong Che ${ }^{3}$, Wensheng Huang ${ }^{1}$ and Bin Shen ${ }^{2, *}$ \\ ${ }^{1}$ Ordnance NCO Academy, Army Engineering University of PLA, 430010, China \\ ${ }^{2}$ Wuhan Donghu University, 430212, China \\ ${ }^{3}$ National University of Defense Technology, 710106, China \\ ${ }^{*}$ Corresponding author
}

\begin{abstract}
At present, various colleges and universities have extensively carried out practical training courses for industrial robots. If students are trained entirely in actual equipment, they will be limited by the number of venues, equipment, complex structure, operation frequency and use safety. This requires students to carry out the necessary safety operation simulation training before carrying out the actual operation. Virtual safety training can effectively simulate the operation of robots, and design corresponding safety hazards to prevent students from misoperation. In this paper, a safety training simulation system is designed for the teaching robot. It provides an effective solution for the safety training of the teaching robot.
\end{abstract} robot

Keywords—simulation; safety operation; VIRTOOLS; teaching

\section{INTRODUCTION}

At present, various colleges and universities have extensively carried out practical training courses for industrial robots. If students are trained entirely in actual equipment, they will be limited by the number of venues, equipment, complex structure, operation frequency and use safety. The traditional video learning is simulated and can not be displayed. It can not complete the interaction between students and equipment, and can no longer meet the needs of the new situation. This requires students to carry out the necessary safety operation simulation training before carrying out the actual operation $^{[1-7]}$.

Virtual safety training can effectively simulate the operation of robots, and design corresponding safety hazards to prevent students from misoperation. The application of virtual reality technology to the safety training of teaching robots is of great significance to the training of industrial robots. This is an important guarantee for training qualified robot operators. It effectively solves the problems of complex equipment structure, high price, limitation of site, quantity and type, and low training efficiency in robot training. Therefore, taking the teaching robot as the object, this paper designs a safety training simulation system, which provides an effective solution for the safety training of the teaching robot.

\section{Overall Structure Design OF SAFETy Training SIMULATION SYSTEM}

According to the system function requirement analysis and the selected realization way, the safety training system is designed mainly for the safety hidden danger of the teaching robot, such as speed limit, soft switch limit, collision restriction and so on. The software design of the system is as follows:

The system uses Visual $\mathrm{C}++6.0$ and the Virtools of Dassault company of France as the development platform of the system. Using Solidworks 3D design software and 3dsmax as modeling and animation generating tools, Access is used as the system database to store the sample part library ${ }^{[8-13]}$.

The simulation of safety training is the omnidirectional simulation of robot operation under the virtual environment. It is the theme of the robot safety operation, and the aim is to lay a solid foundation for the practical training in the future. Safety training simulation technology includes robot six axis motion simulation technology, robot safety hidden danger simulation technology and so on. The safety training simulation completes a series of action simulations according to the predetermined operation process. this simulation mainly uses keyboard operation method to simulate the operation of the robot teaching device, and completes the virtual communication between the teaching device and the robot through the bottom-level function, etc.

The robot itself has a large number of parts. Generally, it belongs to large assembly. The 3D modeling technology provided by Solidworks software has a good effect in dealing with large assembly.

The 3D model of the system is the foundation of the realization of the whole virtual assembly, and its quality directly affects the reality of the virtual environment. Because Virtools has no modeling function, it is necessary to use modeling software to build 3D solid models. But because this article is a mechanical product model, we first use the professional mechanical 3D drawing software Solidworks for modeling, and then import the built model into the 3dsmax, and then from 3dsmax to Virtools. Before establishing the model, a preliminary analysis should be carried out, and the complex mechanical products can be decomposed into several simple parts, and then the three-dimensional modeling of each component is carried out. After the model is established and successfully introduced into the 3dsmax, the model is given the material and the map, thus increasing the authenticity of the model, reducing the unnecessary polygons and improving the refresh rate of the display. 


\section{SimULATION AND CONSTRUCTION OF SAFETY TRAINING}

The system simulates the real operating environment as much as possible. And can design training subjects for typical security risks. In view of some difficult operation steps that are difficult to understand, real shot is taken, and the captured video stream is inserted into the software. After the end of the operation, play the demonstration video, so as to deepen the impression of students' operation, achieve the combination of virtual and reality, and improve the quality of training.

\section{A. Speed Control Simulation}

Speed control is very important in robot operation. If students use high speed to complete manual operation, it is easy to have accidents when the fixture is close to the workpiece. Therefore, the simulation training of this subject is mainly focused on the speed control of manual operation. The system can increase or decrease the speed of the robot in manual or automatic way by pressing the combination of "Q", "A" and "Z". When the student moves the robot to the workpiece at a greater speed, the system alarms and the program stops running. After that, the system calls live video to remind students of incorrect operation. (See Figure I)

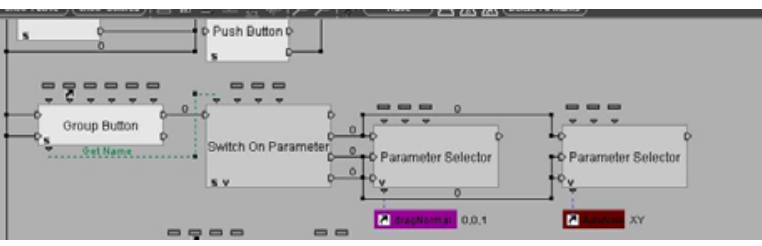

FIGURE I. SPEED ADJUSTMENT OPTIONS

\section{B. Soft Switch Limitation Simulation}

One of the common faults of students in real training is soft switching and limit fault. Many times this kind of fault makes it easy for the actual sensor to tighten the screw thread. Therefore, this training course was designed in safety operation training.

The system aims at restricting the rotation range of each axis of the robot. When the user is about to exceed the range of its activity, the system will be warned, which suggests that the students use the method of robot to rotate safely. Here, we still use the video method to introduce the real clothes.

\section{Simulation of Moving Range Of Robot}

In motion, robots are absolutely not allowed to bump into fixtures such as platforms, brackets, workpieces and so on. The result of the collision is that the robot generates an emergency stop fault and is very difficult to maintain. (See Figure II-III)

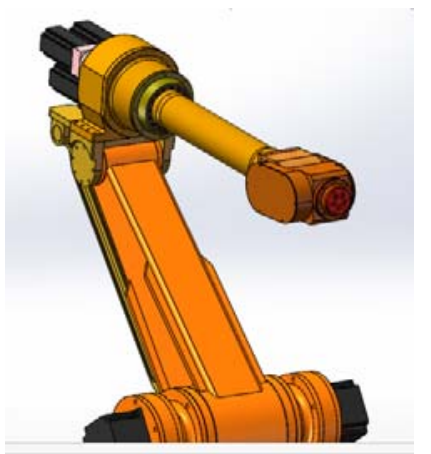

FIGURE II. SPACE POSITION OF ROBOT CLAMP

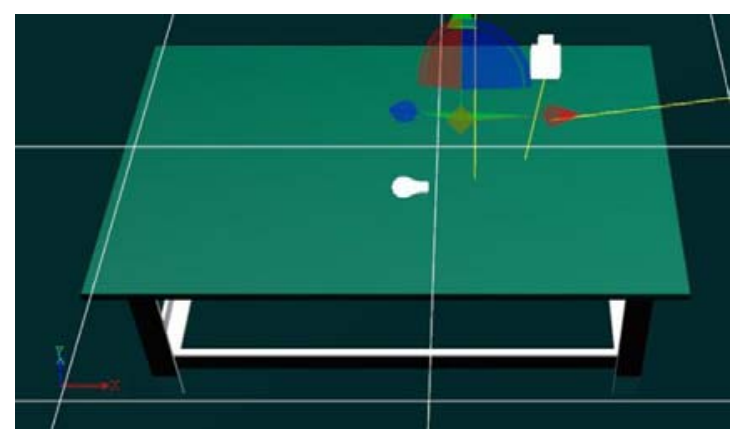

FIGURE III. SPACE POSITION OF ROBOT CONSOLE

The system limits the range of motion of the whole robot. When students simulate operation, if there is a collision fault, they will call the police and call the system to stop the video to finish teaching with virtual reality.

The key technology of robot collision is the collision distance discrimination of parts, which can be realized by using BBS and design VSL provided by Virtools. As shown in Figure IV and Figure V, the key BBS distance judgment and collision judgment are shown in the virtual assembly.

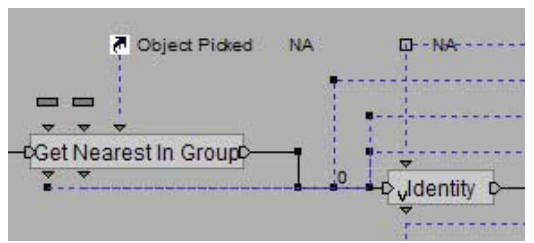

FIGURE IV. DISTANCE JUDGEING

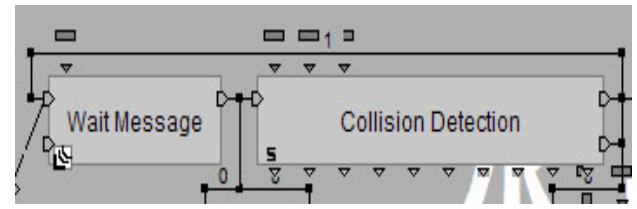

FIGURE V. COLLISION JUDGEING

\section{CONCLUSION}

Compared with the traditional training, the security simulation training has considerable advantages in improving the training flexibility, breaking through the training conditions and reducing the cost of equipment maintenance. 
Virtools software is powerful and easy to operate. It is very suitable for the development of similar systems.

In view of the wide application of virtual maintenance training in practical maintenance training, this system mainly considers that the value of analog equipment can not be too high. It can reduce the cost of analog equipment as much as possible when the training effect is met. At the same time. The system requirements are analyzed from functional completeness, system availability and system reliability. The composition of the system and the framework of the system structure are given. This method provides a new way to realize the safety training system, and has important reference value for the training and popularization of large robots in China.

\section{REFERENCES}

[1] T. M. Cheng, "A fast parametric deformation mechanism for virtual reality applications” [J], Computer \& Industrial Engineering,2008,10(10): $18-26$.

[2] Jeffrey L Wampler, et. Integrating Maintainability and data development[C]. In: Proceedings of the Annual Reliability and Maintainability Symposium, Tamp Bay, 2003. 255-262.

[3] Pan Zhigeng, Cheok Adrian David. Virtual Reality and Mixed Reality for Virtual Learning Environments[J]. Computer \& Graphics, 2006, 30(1): 20-28.

[4] Daniel Cohen-Or. A survey of visibility for walk through applications[J]. IEEE Transactions on Visualization and Computer Graphics. 2003, 9(3): 412-431.

[5] Li J R, Khoo P. Tor B. Desktop Virtual Reality for Maintenance training An Object Oriented Prototype System(V-REALISM)[J]. Computerin Industry, 2003, 52(2): 109-125.

[6] Christopher M C, David C. Virtools Dev User Guide: Version 4.0[z]. Virwols SA, 2006.

[7] Virtools 5.0 Online Heferenee.

[8] Richens P, Nitsche M. Mindstage: Towards a ftmetional virtual architecture[C]. Computer Aided Architectural Design Futures proceedings, 2005: 331-340.

[9] Wutthikornthanawat w'Jinuntuya P,Rongviriyapanieh S, et a1. Multi-user tangible interface for public participation development of low-cost housing project design and planning[C]. Proeeedings of the 12th International Conference on Computer-Aided Architectural Design Research in Asia-Digitization and Globalizatin, 2007: 37-43.

[10] Wang Xi, An Yang. Development ofgame software based on Virtools[J]. Control and Management, 2007, 5(5): 160-162.

[11] Li Xunxiang, Chen Dingfang, Wang Le, et a1. A development framework for V'trtools-based DVR driving systemiC]. Computer Supported Cooperative Work in Design, 2007: 188-196.

[12] Pan VLin Z, Hu Z, et a1. Research on distributed multi. Screendis. play technique based on Virtools[C]. 7th Intemational Conferenee on Computer-Aided Industrial Design and Conceptual Design, 2006: 1-6.

[13] D. U. Silverthom. Teaching and learning in the interactive classroom [J]. Advances in Physiology Education, 2006, 12(30): 135-140. 